Australian Journal of Learning Disabilities, 6 (3), 14-21, 2001

\title{
Instructional Techniques and Service Delivery Approaches for Students with Learning Difficulties
}

\author{
Lorna K.S. Chan, The Hong Kong Institute of Education \\ Kerry Dally, The University of Newcastle
}

\begin{abstract}
This article is the second of two feature articles in this Journal, providing a summary of the literature review contained in Volume Two of the DETYA Report, Mapping the Territory: Primary students with learning difficulties in literacy and numeracy. The first article examined definitions of learning disability and explored the loci of learning difficulties and their influence on literacy and numeracy development. This second article summarizes the last three sections from the review. Section Three explores effective instructional techniques and programs in literacy and numeracy for students with learning difficulties. After that effective service delivery approaches within regular settings are examined in Section Four. Finally issues in program evaluation and measurement of outcomes are addressed in Section Five.
\end{abstract}

\section{Section Three: Effective Instructional Techniques and Programs in Literacy and Numeracy for Students with Learning Difficulties}

Section three surveys the research on effective instructional techniques and programs in literacy and numeracy for students with learning difficulties. General teaching techniques as well as specific programs, designed to address learning difficulties in each of the areas of reading, writing, spelling and maths, are reviewed. Concluding this section is a brief review of medical and other alternative approaches to treating children with learning difficulties.

\section{Reading Recovery}

There have been two main approaches to remediating early reading difficulties. The first approach is typified by the Reading Recovery program, which was introduced by Clay (1985) in New Zealand. The Reading Recovery program focuses on improving children's oral reading skills by introducing them to a hierarchical sequence of texts in a one-to-one tutoring situation. This approach follows the "whole language" philosophy of providing reading instruction with an emphasis on obtaining the meaning from print and learning "decoding" skills incidentally in this context. While there have been favourable results in short-term oral reading improvements, and evidence of long-term positive attitudes to reading (Glynn et al., 1992; Trethowan, Harvey \& Fraser, 1996), this program has also been criticized for failing to show evidence of improvement on broader reading measures, such as comprehension of novel texts (Center et al., 1995).

\section{Phonological awareness training}

The second approach to early reading interventions is based on the premise that the successful acquisition of reading skills relies to a large extent on the ability of the 
beginning reader to identify or decode words that have not been previously encountered. A reader's skill in identifying unfamiliar words is, in turn, dependent on the beginning reader's awareness of the sounds within words (phonological awareness) and efficiency in processing sound-based, or phonological information. Current research has identified that phonological awareness training, for example, teaching children to identify similar sounds in words (c-at and c-ake both start with /c/), assists beginning readers to make sense of the "alphabetic principle", that is, how individual sounds map onto the written letters of the alphabet. Children who enter school with poor phonological awareness are at risk for later reading difficulties and require explicit instruction in both phonological awareness and letter-sound knowledge. Such children may be disadvantaged by the meaning-based wholelanguage approach to reading which focuses on whole words in context. Recent evidence shows that incidental learning of phonological information in the context of reading connected text, does not enable children to acquire a sufficient amount of letter-sound knowledge (Tunmer et al., 1998). However, while phonological awareness training appears to "get children off to a better start" in reading (Castle et al.,1994) it has also been suggested that the acquisition of word identification skills is "necessary but not sufficient" (Torgesen et al., 1997) to ensure comprehension of text. Researchers are now advocating that effective reading interventions should contain both phonological awareness training and instruction in reading comprehension strategies (Torgesen et al., 1997).

\section{Text processing programs}

While in the early years of schooling the focus of reading instruction is on learning to read, in the later years of primary education, the focus is on reading for learning. Skilled reading, or reading for learning, is obviously dependent on accurate and fluent word identification, but also depends on other factors such as, vocabulary development, prior knowledge, and the ability to monitor reading processes and take appropriate action when comprehension starts to falter. In their review of best practices in reading comprehension instruction for students with learning disabilities, Mastropieri and Scruggs (1997) examine the effectiveness of three main types of reading comprehension instruction. Firstly, intervention efforts may be directed towards enhancing the basic skills of the reader, by seeking to improve reading fluency, or extend vocabulary and background knowledge. Although these programs have been effective in improving the targeted skills, they have had limited success in improving reading comprehension outcomes. A second intervention approach is to teach readers how to adapt a text in order to highlight or organize the critical information contained within it. These strategies have been found to be effective in improving comprehension of targeted passages, but do not readily lead to generalized or lasting improvements in comprehending novel or unfamiliar texts. A third focus for comprehension interventions has been to increase students' cognitive skills and metacognitive control by teaching comprehension-fostering and comprehensionmonitoring strategies. This metacognitive approach involves teaching the learner to (a) be aware of task demands, (b) use appropriate strategies to facilitate task completion, and (c) monitor the application of these strategies (Chan, 1991a). Effective comprehension-fostering and comprehension-monitoring strategies include reading previews, advance organizers, summarizing techniques, story mappings, cross-referencing techniques to evaluate internal inconsistencies in texts, and selfquestioning strategies (review in Billingsley \& Wildman, 1990). The effectiveness of 
these interventions has been attributed to a number of common instructional procedures, as well as the inclusion of a self-regulation component.

The instructional procedures considered to be important in strategy training include modeling by the teacher of how and when to use a particular strategy, guided practice for the students in applying the strategy, and providing opportunities for repeated practice and feedback to the students about their performance. While the employment of cognitive strategies may facilitate comprehension, students also need to learn how to spontaneously select and apply an appropriate strategy. Self-instructional training provides a means by which students learn to monitor their comprehension processes and make judgements about the types of strategies they may require (Chan, 1991b). Reciprocal teaching is a technique in which students learn both cognitive and metacognitive strategies to improve reading comprehension. In reciprocal teaching sessions involving small groups of students, the four comprehension strategies of summarising, self-questioning, clarifying and predicting, are modeled overtly by the teacher, with control for the use of the strategies being gradually transferred to the students. Although the effectiveness of teaching cognitive and metacognitve strategies to improve reading comprehension is well supported by empirical research, some authors question whether these 'researcher-delivered' programs can be easily implemented in class contexts (Mastropieri et al. 1996). Mastropieri et al. (1996) further suggest that teachers may require considerable training in techniques such as, modeling, thinking aloud and scaffolding children's learning, which have been primarily employed in one-to-one or small group teaching situations.

\section{Writing programs}

Interventions for writing difficulties have been directed towards improving the skills and strategies necessary for effective planning, writing and revising, and towards improving students' ability to recognize and apply these strategies at appropriate times. As with the interventions for reading difficulties, there have been two main approaches to interventions for writing difficulties. These are firstly, the wholelanguage or process writing approach, and secondly, the more skills-based and teacher directed approach of strategy training. For students with learning difficulties, the process approach to writing has several benefits. Process approaches provide opportunities for regular writing on meaningful tasks, encourage frequent responses from peers and teachers, and emphasize social and contextual factors, which are critical to helping students understand the purposes and goals of writing (Schwartz \& MacArthur, 1990). However, while these factors are important, students with learning difficulties also require direct instruction and guided practice in skills and strategies for planning, producing and revising their written texts (Graham et al., 1991). Strategy instruction, including a self-monitoring component, assists students to develop a repertoire of specific strategies as well as the knowledge and selfregulation to deploy them as needed. There are concerns, however, about maintenance and generalization of strategy usage and especially about the transferability of these one-to-one or small-group writing interventions into regular classes. Recent research suggests that the integration of strategy instruction into a process writing approach may be more effective than either approach in isolation and that such a merger may more successfully meet the needs of students with learning difficulties in regular classes (Graham \& Harris, 1994). 


\section{Spelling programs}

Recent reviews of the spelling intervention literature reveal that a number of instructional techniques hold promise for improving the spelling of students with learning difficulties. These include error-correction procedures with modeling and feedback, limiting word lists to reduce cognitive "overload", explicit teacher-directed training in strategy use and encouraging self-directed study and self-monitoring (Gordon, Vaughn \& Schumm, 1993). It also appears that both computer programs and peers can serve as effective instructional agents (Fulk \& Stormont-Spurgin, 1995). While a whole-language approach appears to provide a "meaningful context" for strategy acquisition, it does not provide adequate instructional input for students who may be deficient in phonological knowledge or who are unable to spontaneously perceive and reproduce the visual patterns of the letter combinations within words (Butyniec-Thomas \& Woloshyn, 1997).

\section{Mathematics programs}

Interventions to ameliorate learning difficulties in mathematics have focused on improving the basic computation skills of students, as well as higher order problem solving. The emphasis in basic computation instruction has shifted from a focus on teaching rote memorization of basic number facts, to teaching students a range of computation strategies, of which retrieval is only one. The most effective type of intervention directed at assisting students to solve mathematical word problems has been the teaching of cognitive and metacognitive strategies. Students show improved performance after explicit instruction in cognitive strategies. Cognitive strategies typically detail a series of steps designed to help students, understand the problem, devise a plan for solving the problem, carry out the computations and then check their solution (Mastropieri, Scruggs \& Shiah, 1991).

\section{Specific mathematics interventions}

A number of instructional practices currently employed in the remediation of learning difficulties in mathematics are reviewed, including direct instruction, precision teaching and anchored instruction. Direct instruction shares several similar instructional techniques with cognitive strategy training such as, corrective feedback, active frequent participation of the learner, teaching skills in a cumulative manner, and providing a reinforcement system. However, whereas cognitive interventions focus on routines and general principles for organizing and processing information, direct instruction focuses on automatizing basic skills as prerequisites for more complex tasks and in order to free attentional resources for higher order processing (Stein, Carnine \& Dixon, 1998). Precision teaching follows a behavioural approach and provides a structured method of recording students progress. Precision teaching is not actually a method of teaching, but provides a systematic way of evaluating instructional techniques and curricula (Lindsley, 1990). Anchored instruction uses short video and audio "anchors" to portray real-life multi-step mathematical problems. The intent of anchored instruction is to provide motivating and contextually situated mathematical problems. It is assumed that the skills and strategies which students acquire through solving "meaningful" problems will more easily transfer to "real-life" situations than knowledge acquired through solving text book examples (Goldman et al., 1997). 


\section{Guiding principles for mathematical instruction}

Some researchers have suggested that a potential cause of learning difficulties in mathematics is a mismatch between mathematics instructional materials and practices, and students learning characteristics (Carnine, 1997). Recent research has identified some guiding principles to ensure that mathematics instruction accommodates the diverse needs of all the children in the class. These include: (a) providing a broad and balanced mathematics curriculum; (b) engaging students in rich, meaningful problem tasks, and (c) encouraging students to discuss and justify their problem-solving strategies and solutions. The limitations of norm-referenced assessment instruments for developing instructional plans for students with learning difficulties, has also been recognised.

\section{Effectiveness of medical interventions and other alternative methods}

Apart from educational interventions for improving the academic outcomes for students with learning difficulties, there are also a number of alternative approaches towards treating children with learning difficulties. One of the generally accepted medical therapies that have been used to treat symptoms of inattention or hyperactivity in children is the use of prescribed psychostimulants. The use of stimulant medication is considered to be an important part of a multi-modal approach to treating children who exhibit both behavioural and academic problems. Although stimulant medication is effective in reducing behaviours that disrupt or prevent school learning, medicated children may still require remedial programs and a range of other family or school-focused interventions (Cantwell, 1996).

There also exist a range of 'controversial' therapies that are characterized by their tendency to attribute the complex characteristics of learning difficulties to one specific cause, which can therefore be treated relatively easily. These approaches, which are usually based on unproven theories and which commonly lack evidence from research to validate the effectiveness of the treatments, include: optometric training; dietary interventions; and neuromotor therapies. Optometric training attributes reading disabilities to problems in visual perceptual processes, and treatments may involve sensory-motor perceptual-training techniques or the prescription of coloured lenses (Irlen \& Robinson, 1996). Dietary interventions have mainly been used to treat hyperactivity in children. However, there has been no research data to support the effectiveness of elimination diets such as the Feingold diet, or the use of trace elements and megavitamins to supplement children's diets (Kavale \& Forness, 1983). Neuromotor therapies refer to a group of treatments that are based on the concept that stimulating specific sensory inputs, or exercising specific motor patterns can retrain or improve the central nervous system. Therapies such as patterning, sensory integration therapy and applied kinesiology have not proven to be effective in treating learning difficulties (Silver, 1987). The danger in the lure of these appealing but ineffective treatments is that the pursuit of controversial therapies may distract or prevent parents from seeking conventional educational remedies for their children. 


\section{Section Four: Effective Service Delivery Approaches Within Regular Settings}

In Section Four various effective approaches of delivering special educational services to students with learning disabilities within regular class settings are reviewed. These include collaborative consultancy or team teaching models, part-time withdrawal models, peer-tutoring models, parent partnership models, and the use of technological aids.

\section{Collaborative consultancy /team teaching models}

Consultation has been described as a triadic model in which the special educator indirectly brings about changes for the student through the regular class teacher (Coben, Thomas, Sattler \& Morsink, 1997). In this model the consultant is the special educator who has the expertise regarding strategies to meet the needs of the student (client) and the teacher (consultee) is the one attempting to implement the strategies and work with the student directly. To ensure a more equal relationship characterised by mutual trust, communication and shared responsibilities between regular and special educators in meeting the needs of students with learning disabilities, collaboration models were preferred. In this model, the regular and the special educators work together to diagnose the student's needs and to plan the intervention strategies. But this approach still involves only one of the collaborative partners, usually the regular class teacher, working directly with the student in the classroom.

The team-teaching approach requires the two partners to collaborate in working jointly and directly with the student in the classroom. Thomas, Correa, \& Morsink (1995) define their model of 'interactive teaming' as a "mutual or reciprocal effort among and between members of a team to provide the best possible educational program for a student. The strength of this approach is the potential for effective, comprehensive and cohesive services when all the people involved work together instead of functioning as separate individuals or disciplines.

For collaborative consultation and team teaching approaches to work, the collaborative partners must have a clear understanding of their respective roles and must perceive their roles as appropriate and meaningful. A common willingness to participate is also necessary. Most importantly, it is essential that the collaborating partners have common planning time in preparing for the shared teaching responsibilities and in jointly taking up responsibilities for the diagnosis, design, implementation and evaluation of programs for students with learning difficulties. Zigmond and Baker (1996) argued, however, that full inclusion models, with team teaching and often joint planning between general and special education teachers, may not be able to provide the carefully planned, focused, intensive and goal-directed instruction that students with learning disabilities require. Results of their qualitative study on full-inclusion elementary school models suggest that the special programs available for students with learning disabilities in their study only involved changed assignments, activities and tests. Zigmond and Baker concluded that the changes were "superficial, impromptu, and hardly likely to have a lasting impact or to achieve long-term goals" (p.32). 


\section{Part-time withdrawal models}

In part-time withdrawal models, students are enrolled in a regular class, but are 'withdrawn' from this class for some portion of their school day, to receive more intensive remedial programs in a resource room setting. The effective components of part-time withdrawal models include: (a) the employment of highly trained professionals who are capable of diagnosing problems and planning and implementing appropriate programs; (b) programs which teach students the skills they need to cope with the requirements of their mainstream class; and (c) effective teaching techniques which will allow students to acquire a significant number of skills and strategies in a short period of time. The ultimate aim of part-time withdrawal programs is to lead students towards independent learning so they can eventually attend mainstream classes on a full-time basis.

There have been positive findings from some researchers indicating that resource room programs for students with learning difficulties are achieving their intended outcomes (Carlberg \& Kavale, 1980). However, other researchers (cited in Jenkins \& Heinen, 1989) have criticized this model for a number of shortcomings, including: disrupting classroom instruction and failing to coordinate the resource room programs with the regular class curriculum; absolving classroom teachers of responsibility for instructing low performing students; and attaching stigmas to the children who are pulled out. It has been suggested that 'full inclusion', that is, where students with learning disabilities attend mainstream classes in a full-time capacity, will improve the social acceptance of students with disabilities, as well as improving the quality of instruction in the classroom for all students (Whinnery et al. 1995). However, Zigmond \& Baker (1996) question whether the constraints of the regular class setting, such as large numbers of students, less opportunities for individualized instruction or feedback, and a more distracting environment, will permit the same intensity of instruction that can be offered and provided in resource room contexts. The literature suggests that no single model is yet able to meet the diverse needs of all students, and that students with learning difficulties are best served by having access to a range of services that can operate simultaneously and flexibly.

\section{Peer tutoring models}

Peer tutoring involves grouping students into pairs, where one student acts as a tutor, and provides instruction, and the other student, or tutee, receives instruction. Peer tutoring has positive value for students with learning difficulties, whether they assume the role of tutor or tutee. The benefits provided by peer tutoring include academic as well as social gains. With the support of a skilled and well-trained tutor, students with learning disabilities are more likely to stay on task, to monitor and correct their responses and to master targeted content (Byrd, 1990). Students with learning difficulties also make effective tutors when the tutoring tasks are within their range of competence, and may gain considerable self-esteem and positive attributional beliefs from well structured tutoring sessions (Cook et al., 1985-86). There are also reciprocal benefits for students without learning difficulties, who gain from the cognitive challenge involved in providing explanations (Cole \& Chan, 1990), and who, according to teacher reports, appear to become more accepting of students with learning difficulties during peer tutoring programs (Vadasy et al., 1997). 
The effectiveness of peer tutoring relies on adequate pre-training of students, a structured sequence of activities for the tutoring sessions, and the willingness and organizational skills of the teacher and the students. Implementation of peer tutoring may require a considerable investment of the teachers' time, and the support of the school administration would appear to be a necessary prerequisite (Fuchs et al., 1997). Although peer tutoring has the potential to address the needs of a range of ability levels, there may be problems of boredom for high-achieving students, or problems of frustration for their low-achieving peers. While careful monitoring and program adjustment by the teacher may alleviate some of these problems, researchers suggest that too many modifications may jeopardize the programs' empirically proven effectiveness.

Fuchs et al. (1997) caution that students with severe learning disability may not profit from peer tutoring situations and recommend more intensive interventions provided by professionally trained adults. Peer tutoring may be a valuable "supplement" to traditional educational instruction, but should not be regarded as a "substitute" for quality educational practices.

\section{Parent partnership models}

The parent partnership model aims to optimize educational outcomes for students, by establishing communication and cooperation between schools and families. When parents are involved in schooling, students have shown improvements in academic perseverance and participation in classroom learning activities, test scores, attitudes towards schoolwork, behaviour and self-esteem (Christenson et al., 1997). Although there appears to be willingness on the part of parents and teachers to engage in dialogue and activities to promote educational opportunities for children, successful relationships between schools and families may require considerable organization and administrative support, and rely on individual levels of interpersonal skills.

Parents require options regarding the degree of involvement they would prefer, and teachers as well as parents, may require training to develop capacities for cooperative problem solving. In partnership models, parents needs should be considered, parent anxiety should be acknowledged and parent input should be valued (Greaves, 1995). Following a planned implementation process may facilitate the establishment of parent partnership programs. The development of effective parent partnerships can enhance students school success, as well as establishing mutually satisfying and constructive relationships between schools and families.

\section{Use of technological aids}

There are a number of different ways that technology can be employed in the education of students with learning difficulties. Raskind, Herman and Torgesen (1995) have classified the main purposes for technology in the education of students with learning difficulties into three main categories: (a) remediation/instruction; (b) compensation; and (c) fostering special talents.

\section{The role of technology in remediation and instruction}

One of the greatest developments in technological interventions for students with learning difficulties has been in computer applications that provide instruction or 
remediation in areas of deficiency such as reading, maths, writing and spelling. The individualised nature of computer-assisted instruction (CAI) makes this medium particularly appealing for students with special learning needs. CAI can provide: personalized instruction that is commensurate with students ability levels; large amounts of highly focused, carefully sequenced and monitored instruction; practice on a variety of academic tasks; and direct and immediate feedback. The research indicates that computer-based reading programs have demonstrated effectiveness in improving phonological awareness, decoding and word recognition skills in beginning or struggling readers (Torgesen \& Baker, 1995; Olson \& Wise, 1992). In mathematics instruction, CAI has not proven to be superior to teacher-directed learning, but is able to provide teachers with an effective and feasible means of extending limited instructional resources. Videodisc technology has allowed mathematical problem solving to be embedded in "real-life" contexts, thus assisting in the transfer of mathematical skills and knowledge to new problem situations. Hypermedia environments that can incorporate sound, animation, photographic images and video clips can assist students to conceptualize word problems or solve computational problems by representing the problems with tangible graphics, which can be manipulated on the computer screen (Babbitt \& Miller, 1996).

The most common form of technology used to assist students with difficulties in writing and spelling is computers in combination with word processing programs, synthesized speech or internet access. At this stage the promise and potential of technology to provide instruction for students with learning difficulties or to remediate areas of deficiency, is greater than the proven benefits. However, the emerging results suggest that technology is meeting many of it's promises and that it provides an appealing and effective medium for teaching children who struggle to learn via traditional modes of instruction. The efficacy of computer-assisted instruction is significantly affected by the quality of the software that is employed, and teacher involvement is crucial to the successful implementation of all technological aids (Raskind et al., 1995).

\section{Technological Aids as Compensatory Devices}

As well as being employed to facilitate instructional and remedial programs, technology can also be used for the purpose of compensating for weaknesses (Raskind \& Higgins, 1995). Some examples of compensatory technology include the provision of technological aids such as: calculators, for students with poor computational skills so that they can bypass weaknesses in basic computation to solve more difficult word problems; word processing programs which offer spelling and editing assistance to students with poor spelling or handwriting; speech-recognizing computers which convert spoken language to computer text, for students with fluent oral skills but disabilities in written communication; and access to information via audio-tapes, audio CDs, films, videos, television, CD-ROM based reference "books" and databases on the Internet as an alternative to reading textbooks for students with reading fluency and reading comprehension difficulties (Lewis, 1998). According to Raskind and Higgins (1995) the use of such technologies has the potential to increase independence, enhance self-concept, and promote social interaction. Lewis maintains that learning disabilities can impose barriers to full participation in academic activities, and that assistive technology offers students ways to surmount these barriers. 
Although it appears that assistive technology offers students an empowering alternative to the frustration of struggling to master skills and tasks which present significant and ongoing difficulties and challenges, there may be ethical conflicts and practical obstacles relating to the effective implementation of assistive technology, which also need to be considered. Torgesen (1993, cited in Raskind \& Higgins, 1995) raised the issue of the difficulty in determining when is the appropriate time to replace instructional/remedial approaches with assistive technologies.

\section{The role of technology in fostering special talents}

The majority of the research literature in relation to technology and the education of students with learning difficulties, is concentrated on the role of technology in remediating or compensating for, weaknesses and deficits. Some authors argue that technology should be used in a more 'holistic' way in order to design an educational approach that is 'compatible with life' and that is not just focused on school-based measures of literacy (Poplin, 1995). Poplin argues that the current emphasis on 'deficit-driven' instruction is not only limiting, but also oppressive for students who continue to struggle with the requirements of a print-focused curriculum. Poplin considers that the real value of technology lies in it's potential to accentuate the strengths of individuals with learning disabilities, and that the educational focus for such students should change 'from disability to ability'. Technological aids such as computers with enlarged memories, increased speed and enhanced graphic and sound capabilities, may be utilized to foster talents in the areas of visual arts, music or divergent thinking (Raskind \& Higgins, 1995).

Although there is optimism about the current and future role of technology in the education of students with learning difficulties, the literature also notes two major implementation difficulties. Firstly, the effective use of technology relies to a large extent on the ability of teachers to select and employ appropriate technological aids and to integrate their use with class programs and practices. Howell (1996) reports that national surveys and reviews of the literature in the United States indicate that teachers are not receiving the inservice and preservice training they require. Secondly, technological aids are not yet widely available to schools or evenly distributed across educational contexts, and, as Lewis (1998) astutely observes 'technology is worthless if its potential users are denied access to it' (p. 23).

\section{Section Five: Issues in Program Evaluation and Measurement of Outcomes}

Program outcomes may be defined and measured in different ways and from different perspectives. Researchers who support quantitative methods tend to conduct interventions which are "empirically" valid and focus on outcomes on which measurable and quantifiable data can be obtained, while researchers supporting qualitative methodologies and a "holistic" approach, argue that research should be discovery oriented, should include subjective data and be conducted in naturalistic conditions. A third perspective is provided by class teachers who tend to employ a more basic assessment process - does the intervention work, and is it feasible to implement in the classroom?

From a quantitative perspective, four main questions arise concerning program outcomes. Firstly, does the intervention lead to improvements in students performance? Secondly, do the newly acquired or enhanced skills and strategies 
transfer to situations other than post-intervention assessments? Thirdly, are the gains maintained? And fourthly, does improved performance in the targeted skills or strategies lead to improvements in other types of learning, or higher-level processing? Researchers need to consider, not just immediate post-intervention improvements, but whether their intervention has produced transferable and lasting gains in the academic performance of students, on novel tasks and in contexts other than experimental testing conditions. There is disagreement in the literature about the validity of using experimenter-developed tests to assess learning outcomes, with some researchers arguing that such measures reflect a "practice" effect that tends to inflate the significance of results.

Researchers supporting qualitative methodologies assert that assessment measures should not be confined solely to a focus on individuals and their performance on achievement tests. These authors suggest that a broader array of outcome measures, which are not necessarily quantifiable, should be considered including: students and teachers attitudes to remedial programs; students performance in holistic and authentic activities; and the collaborative roles of students and teachers in the social context of the classroom. The views of students are an important outcome to measure, because if students do not view the skills or strategies they are being taught as useful and easy to use, they probably will not use them. Similarly, the knowledge, experience and attitudes of teachers are also important factors, because of the teacher's crucial role in implementing remedial programs.

While researchers investigating interventions for students with learning difficulties may define the effectiveness of a program in terms of enhanced student outcomes, it is also critical to consider the practical context in which the intervention will need to be implemented in the normal classroom. The design and evaluation of programs thus have to address the day-to-day constraints of a 'real' classroom and include the professional development needs of teachers to ensure that program effectiveness can be maintained.

The two articles in this Volume of the Learning Difficulties Journal present a summary of the literature review from the DETYA Report - Mapping the Territory. These articles have provided only a brief analysis of the difficulties in literacy and numeracy acquisition experienced by primary school students with learning disabilities, and the identification of successful intervention strategies to cater for their needs. A more comprehensive analysis and discussion of these issues is contained in the complete literature review in Volume 2 of the DETYA report.

\section{REFERENCES}

Babbitt, B.C. \& Miller, S.P. (1996). Using hypermedia to improve the mathematics problem-solving skills of students with learning disabilities. Journal of Learning Disabilities, 29 (4), 391-401,412.

Butyniec-Thomas, J. \& Woloshyn, V.E. (1997). The effects of explicit-strategy and whole-language instruction on students' spelling ability. The Journal of Experimental Education, 65(4), 293-302.

Byrd, D.E. (1990). Peer tutoring with the learning disabled: A critical review. Journal of Educational Research, 84(2), 115-118. 
Cantwell, D.P. (1996). Attention deficit disorder: A review of the past 10 years. Journal of the American Academy of Child and Adolescent Psychiatry, 34(10), 978-987.

Carlberg, C. \& Kavale, K. (1980). The efficacy of special versus regular class placement for exceptional children: A meta-analysis. The Journal of Special Education, 14, 295-309.

Carnine, D. (1997). Instructional design in mathematics for students with learning disabilities. Journal of Learning Disabilities, 30 (2), 130-141.

Castle, J.M., Ricah, J., \& Nicholson, T. (1994). Getting off to a better start in reading and spelling: The effects of phonemic awareness instruction within a whole language program. Journal of Educational Psychology, 86(3), 350-359.

Center, Y., Wheldall, K., Freeman, L., Outhred, L., \& McNaught, M. (1995). An evaluation of reading recovery. Reading Research Quarterly, 30 (2), 240-263.

Chan, L.K.S. (1991a). Metacognition and remedial education. Australian Journal of Remedial Education, 23(1), 4- 10.

Chan, L.K.S. (1991b). Promoting strategy generalization through self-instructional training in students with reading disabilities. Journal of Learning Disabilities, 24(7), 427-433.

Christenson, S. L., Hurley, C.M., Sheridan, S.M., \& Fenstermacher, K. (1997). Parents and school psychologists' perspectives on parent involvement activities. School Psychology Review, 26(1), 111-130.

Clay, M. (1985). The early detection of reading difficulties. Auckland, New Zealand: Heinemann.

Cole, P.G. \& Chan, L.K.S. (1990). Methods and strategies for special education. Victoria, Australia: Prentice Hall.

Cook, S., Scruggs, T., Mastropieri, M., \& Casto, G. (1985-86). Handicapped students as tutors. The Journal of Special Education, 19, 483-492.

Fuchs, D., Fuchs, L., Mathes, P.G., \& Simmons, D.C. (1997). Peer-assisted learning strategies: Making classrooms more responsive to diversity. American Educational Research Journal, 34(1), 174-206.

Fulk, B.M., \& Stormont-Spurgin, M. (1995). Spelling interventions for students with disabilities: A review. The Journal of Special Education, 28(4), 488-513.

Glynn, T., Bethune, N., Crooks, T., Ballard, K., \& Smith, J. (1992). Reading Recovery in context: implementation and outcome. Educational Psychology, $12(3,4) 249-261$.

Goldman, S.R., Hasselbring, T.S, \& the Cognition and Technology Group at Vanderbilt. (1997). Achieving meaningful mathematics literacy for students with learning disabilities. Journal of Learning Disabilities, 30 (2), 198-208.

Gordon, J., Vaughn, S., \& Schumm, J S. (1993). Spelling interventions: A review of literature and implications for instruction for students with learning disabilities. Learning Disabilities Practice, 8(3), 175-181.

Graham, S., \& Harris, K.R. (1994). The effects of whole language on children's writing: A review of literature. Educational Psychologist, 29(4), 187-192.

Graham, S., Harris, K.R., MacArthur, C.A., \& Schwartz, S. (1991). Writing and writing instruction for students with learning disabilities: Review of a research program. Learning Disability Quarterly, 14, 89-114.

Greaves, D. (1995). Enhancing the parent-professional relationship. Australian Journal of Remedial Education, 27(1), 16-19.

Howell, R. (1996). Technological aids for inclusive classrooms. Theory Into Practice, 35(1), 58-65. 
Irlen, H. \& Robinson, G.L. (1996). The effect of Irlen coloured filters on adult perception of workplace performance: A preliminary survey. Australian Journal of Learning Disabilities, 1(3), 7-16.

Jenkins, J.R. \& Heinen, A. (1989). Students' preferences for service delivery: Pullout, in-class or integrated models. Exceptional Children, 55(6), 516-523.

Kavale, K.A. \& Forness, S.R. (1983). Hyperactivity and diet treatment: A metaanalysis of the Feingold hypothesis. Journal of Learning Disabilities, 16(6), 324-330.

Lewis, R.B. (1998). Assistive technology and learning disabilities: Today's realities and tomorrow's promises. Journal of Learning Disabilities, 31(1), 16-26.

Lie, A. (1991). Effects of a training program for stimulating skills in word analysis in first-grade children. Reading Research Quarterly, 26(3), 234-250.

Lindsley, O.R. (1990). Precision teaching: By teachers for children. Teaching Exceptional Children, 22 (3), 10-15.

Mastropieri, M.A., \& Scruggs, T.E. (1997). Best practices in promoting reading comprehension in students with learning disabilities 1976 to 1996. Remedial and Special Education, 18 (4), 197-213.

Mastropieri, M.A., Scruggs, T.E., Bakken, J.P., \& Whedon, C. (1996). Reading comprehension: A synthesis of research in learning disabilities. Advances in Learning and Behavioural Disabilities, 10B, 201-227.

Mastropieri, M.A., Scruggs, T.E., \& Shiah, S. (1991). Mathematics instruction for learning disabled students: A review of research. Learning Disabilities Research \& Practice, 6. 89-98.

Olson, R.K. \& Wise, B. (1992). Reading on the computer with orthographic and speech feedback: An overview of the Colorado remediation project. Reading and Writing, 4(2), 107-144.

Poplin, M.S. (1995). The dialectic nature of technology and holism: Use of technology to liberate individuals with learning disabilities. Learning Disability Quarterly, 18, 131-140.

Raskind, M.H., Herman, K.L., \& Torgesen, J.K. (1995). Technology for persons with learning disabilities: Report on an international symposium. Learning Disability Quarterly, 18, 175-184.

Raskind, M.H \& Higgins, E.L. (1995). Reflections on ethics, technology, and learning disabilities: Avoiding the consequences of ill-considered action. Journal of Learning Disabilities, 28(7), 425-438.

Schwartz, S.S. \& MacArthur, C.A. (1990). They all have something to say: Helping learning disabled students write. Academic Therapy, 25(4), 459-471.

Silver, L.B. (1987). The "magic cure": A review of the current controversial approaches for treating learning disabilities. Journal of Learning Disabilities, 20(8), 498-504, 512.

Stein, M., Carnine, D., \& Dixon, R. (1998). Direct instruction: Integrating curriculum design and effective teaching practice. Intervention in School and Clinic, 33(4), 227-234.

Trethowan, V., Harvey, D., \& Fraser, C. (1996). Reading Recovery: Comparison between its efficacy and normal classroom instruction. The Australian Journal of Language and Literacy, 19(1), 29-37.

Torgesen, J.K. \& Baker, T.A. (1995). Computers as aids in the prevention and remediation of reading disabilities. Learning Disability Quarterly, 18, 76-87. 
Torgesen, J. K., Wagner, R. K., \& Rashotte, C. A. (1997). Prevention and remediation of severe reading disabilities: Keeping the end in mind. Scientific Studies of Reading, 1(3), 217-234.

Tunmer, W.E., Herriman, M.L., \& Nesdale, A.R. (1988). Metalinguistic abilities and beginning reading. Reading Research Quarterly, 23 (2), 134-158.

Vadasy, P.F., Jenkins, J.R., Antil, L.R., Wayne, S.K., \& O'Connor, R.E. (1997). The effectiveness of one-to-one tutoring by community tutors for at-risk beginning readers. Learning Disability Quarterly, 20, 126-139.

Whinnery, K.W., King, M., Evans, W.H., \& Gable, R.A. (1995). Perceptions of students with learning disabilities. Inclusion versus pull-out services. Preventing School Failure, 40(1), 5-9.

Zigmond, N. \& Baker, J.M. (1996). Full inclusion for students with learning disabilities: Too much of a good thing? Theory Into Practice, 35(1), 26-34. 